\title{
Hypothesized mechanisms explaining poor prognosis in type 2 diabetes patients with COVID-19: a review
}

\author{
Giuseppe Lisco $\mathbb{1}^{1} \cdot$ Anna De Tullio $\mathbb{1}^{2} \cdot$ Vito Angelo Giagulli $\mathbb{D}^{2,3} \cdot$ Edoardo Guastamacchia $\mathbb{(}^{2}$. \\ Giovanni De Pergola $\mathbb{C}^{4} \cdot$ Vincenzo Triggiani $\mathbb{C}^{2}$
}

Received: 23 April 2020 / Accepted: 28 July 2020 / Published online: 10 August 2020

(c) Springer Science+Business Media, LLC, part of Springer Nature 2020

\begin{abstract}
Purpose Epidemiological data suggest that comorbid patients, mostly those with type 2 diabetes (T2D), are predisposed to poor prognosis in Coronavirus disease 2019 (COVID-19), leading to serious healthcare concerns. The aim of the present manuscript is to review the main relevant mechanisms possibly contributing to worsen the clinical course of COVID-19 in T2D.

Results Poor glucose control, high glycaemic variability and diabetes-related comorbidities at baseline, particularly cardiovascular diseases and obesity, contribute in worsening the prognosis in the above-mentioned cluster of patients. Moreover, both a lower efficient innate immune system response and cytokine dysregulation predispose patients with T2D to impaired viral clearance and more serious pulmonary and systemic inflammation once the SARS-CoV-2 infection occurred. Inconclusive data are currently available for specifically indicate or contraindicate concurrent medications for managing T2D and its comorbidities in infected patients.

Conclusions T2D individuals should be considered as more vulnerable to COVID-19 than general population, and thus require adequate advices about hygienic tips to protect themselves during the pandemic. A careful management of glucose levels and diabetes-related comorbidities remains essential for avoiding further complications, and patient monitoring during the pandemic should be performed also at distance by means of telemedicine. Further studies are needed to clarify whether medications normally used for managing T2D and its associated comorbidities could have a protective or detrimental effect on COVID-19 clinical course.
\end{abstract}

Keywords COVID-19 $\cdot$ Diabetes mellitus $\cdot$ Cardiovascular disease $\cdot$ Obesity $\cdot$ Immune response $\cdot$ GLP-1RAs

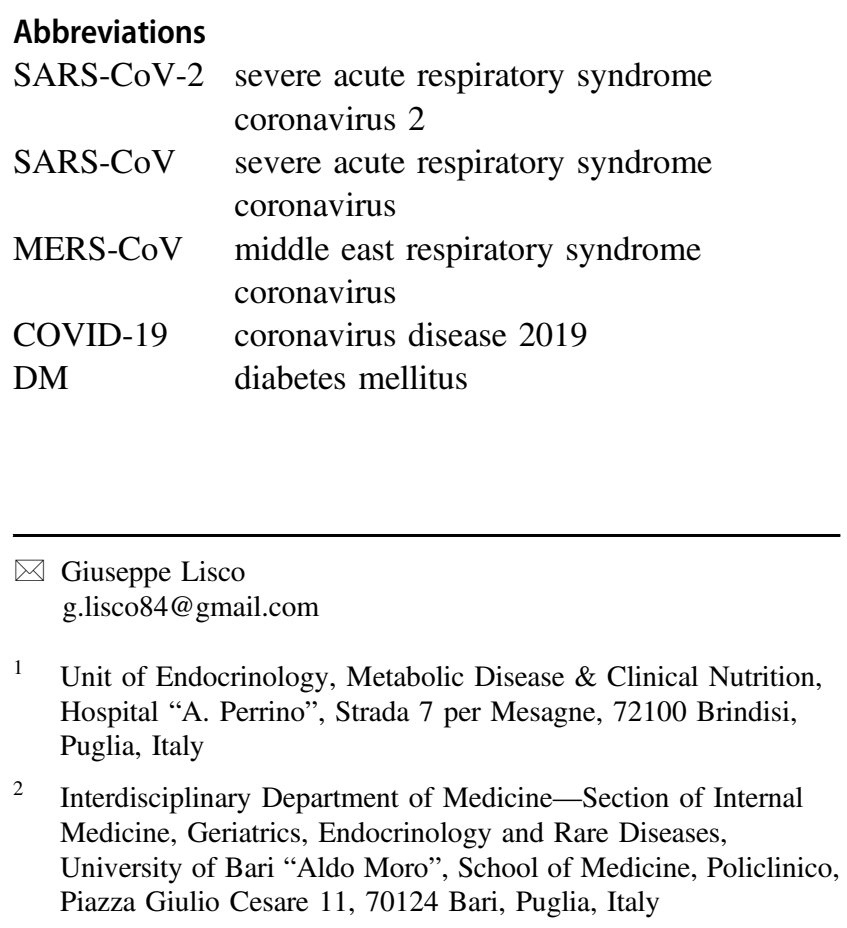

T2D

IL

NK

ACE2

DPP-IV

GLP-1RA

MYD88 type 2 diabetes

interleukin natural killer angiotensin-converting enzyme type 2 dipeptidyl peptidase IV glucagon-like peptide 1 receptor agonist myeloid differentiation primary response 88
3 Outpatients Clinic of Endocrinology and Metabolic Disease, Hospital "F. Jaja", Via Edmondo de Amicis 36, 70014 Conversano, Bari, Puglia, Italy

4 Department of Biomedical Sciences and Human Oncology, Section of Internal Medicine and Clinical Oncology, University of Bari Aldo Moro, Piazza Giulio Cesare 11, 70124 Bari, Puglia, Italy 


\section{Background}

Firstly identified and characterized as 2019-nCOV [1], human severe acute respiratory syndrome coronavirus 2 (SARS-CoV-2) has been reported as a novel infective agent arisen at the end of the 2019 [2]. SARS-CoV-2 is a positivesense, single strand, enveloped RNA virus belonging to the family of Coronaviridae, and is the 7th beta-coronavirus recognized to infect humans [3]. First metagenomic RNA sequencing of SARS-CoV-2 showed the single-strand RNA consisted of 29,906 nucleotides, and was closely related to a group of bat SARS-like coronaviruses $(89,1 \%)$ [4]. Further observations confirmed that SARS-CoV-2 was closely related $(88 \%)$ with two bat SARS-like coronavirus (bat-SLCoVZC45 and bat-SL-CoVZXC21), but was distant from other two human coronaviruses responsible for severe infective pneumonia: SARS-CoV (79\%) and Middle East respiratory syndrome coronavirus (MERS-CoV) (50\%) [5]. A high grade of homology between genomic sequences of SARS-CoV-2 form different patients (99.98\%) has also been reported, thus confirming a human-to-human transmission of the novel infective agent [5]. Phylogenetic analysis suggested that SARS-CoV-2 progenitors circulated in animal host including bats [6], snakes, Malayan pangolins, civets, mouse [7, 8], and underwent to a naturally occurred selection before the zoonotic spillover finally adapting to persistently infect the new host [9]. Official epidemiological report declared that the early cases of infections were detected in December 2019, and involved people who worked or visited the Hua Nan South China Seafood Market [10], in Wuhan capital city (Hubei province; People's Republic of China). However, it remains still debated whether the zoonotic spillover might have been occurred in other places [11], particularly in Southeast Asia [12], and consequently SARS-CoV-2 infection might have been imported to Wuhan. Epidemiological analysis showed a marked widespread of the infection within community places due to a large human-to-human transmission [13] and Wuhan rapidly became the hub of a new pneumonia outbreak [14]. Due to a consistent widespread of detected cases among several countries, the World Health Organization declared the state of pandemic on March 11, 2020 when confirmed cases raised up to 118,000 , and SARSCoV-2 spread into 114 countries [15].

\section{COVID-19 and clinical matter}

Clinical manifestations of the novel coronavirus disease 2019 (COVID-19) include fever (87\%), cough (58\%), dyspnoea (38\%), muscle soreness $(35 \%)$, chest distress $(31 \%)$ in a context of bilateral pneumonia $(76 \%)$ with ground glass opacification (70\%) at CT scan due to lung interstitial involvement [16]. Autoptic studies described macroscopic features of pleuro-pericarditis, lung consolidation, oedema with overall increased pulmonary weight; while microscopic hallmarks are characterized by pneumocyte hyperplasia, lymphocytic and multinucleated giant cells infiltration, hyaline membranes [17-19]. Other signs and symptoms of COVID-19 include acute conjunctivitis [20, 21]; diarrhoea, abdominal pain/discomfort and vomiting [22-24]; convulsion, headache, muscle soreness [25]; diffuse erythematous rush and widespread urticaria [26]; acute kidney injury [27, 28]; pharyngodynia, nasal congestion with rhinorrhoea and smell/taste impairment [29]. SARS-CoV-2 may directly affect myocardial tissue, and significantly complicate the prognosis of underlying cardiovascular diseases [30, 31]. SARS-CoV-2 infection usually occurs asymptomatically or mildly symptomatic form of the disease but in predis posed patients with specific clinical conditions, a serious clinical course could be observed thus leading to worse prognosis or death [12]. Worldwide reported case-fatality rate for COVID-19 differs considerably among geographical areas [32], and could be attributable to several variables, such as testing strategies for screen suspected cases and identification of infectious patients (statistical); accessibility to intensive care according to restricted national healthcare system capacities (organization); baseline patient age and comorbidities (medical) [33, 34]. From the latter point of view, a poor prognosis is usually observed in elderly patients [35] and worldwide age-specific case-fatality rate occurred very high among patients with one or more underlying chronic diseases including cardiocirculatory, renal, pulmonary, central nervous system and mental illness, diabetes mellitus (DM) and malignancies [36, 37]. According to the data shared by the Italian National Institute of Health, patients who died while tested positive for SARS-CoV-2 exhibited an elevated mean age (78.5 years old), mostly men (70\%) and with one or more pre-existent chronic diseases (2.7 in mean) [38]. Of these, blood arterial hypertension (78\%) and DM (34\%) were the most commonly reported clinical comorbidities, followed by ischaemic heart disease $(30 \%)$ and atrial fibrillation $(22 \%)$. The leading cause of deaths was attributable to acute respiratory distress (97\%) [38].

\section{Epidemiological considerations in patients with type 2 diabetes}

The global estimated prevalence of T2D accounts for more than 450 millions affected patients corresponding to $9.3 \%$ of the worldwide population [39]. Therefore, the number of patients with T2D who will contract SARS-CoV-2 infection is expected to be considerable, and should increase 
over time. T2D per se does not increase the risk of contracting SARS-CoV-2 infection but could exacerbate the clinical course of COVID-19 leading to a detrimental prognosis [40]. Indeed, the frequency of diabetes in patients with COVID-19 has been reported to $9-12 \%$ [41-43], raising up to $16-20 \%$ in hospitalized patients including those who required intensive care for severe disease [44, 45]. More recently, data collected from nine hospitals from Seattle-area in the United States demonstrated that $58 \%$ of patients who required hospitalization for respiratory symptoms attributable to COVID-19 had T2D [46]. In severely ill patients with COVID-19 a preexistent T2D was observed in about $35 \%$ of the cases and, according to the results of an univariate analysis, the presence of T2D resulted a significant risk factor for poor prognosis in this clinical setting (OR 8.14; $p<0.0001$ ) [47]. DM has also been reported as the main clinical condition observed in non-survived patients with COVID19 (22\%) [48], thus resulting one of the most frequently associated comorbidity in COVID-19 deceased patients [33]. This concern has been further confirmed by the results of a cohort study among 85 fatal cases of COVID19 in Wuhan, hence defining DM as a potentially harmful comorbidity predisposing to worse clinical course or death once SARS-CoV-2 infection occurred [49].

Different hypothesis should be considered for explaining this clinical phenomenon, including glucose control at baseline and during the infection course, pathophysiology and immune system response in SARS-CoV-2 infected patients with T2D, diabetes-related comorbidities and concomitant medications. Herein, a point-to-point discussion about these putative mechanisms has been carried out.

\section{Glucose control}

Epidemiological data showed that $\mathrm{T} 2 \mathrm{D}$ represents a risk factor for infectious diseases, mostly with bacterial aetiology, particularly at the level of skin and soft tissue, genitourinary, gastrointestinal and respiratory systems [50]. Moreover, life expectancy in individuals with T2D may be affected due to infectious diseases and in certain clusters of patients, such as in elderly with T2D, the leading cause of mortality is attributable to severe pulmonary infections rather than other highly prevalent comorbidities, including cardiovascular diseases and malignancies [51]. On the other hand, DM increases the cumulative risk of medical consultation, hospital admission, intensive care requirement and poor prognosis because of pandemic influenza [52]. Further data reported that airways and pulmonary infections with different aetiologies, including SARS and MERS, were more frequently diagnosed in T2D patients, also showing a severe clinical course [53-56]. In DM, hyperglycaemia is considered one of the most important factor in determining this burden [57]. Indeed, osteomyelitis, soft tissues infections, endocarditis, tuberculosis and sepsis are most commonly observed in diabetic patients with poor glycaemic control compared to those who achieve better glucose management, and a worse glucose control contributes to increase the rate of hospitalization and mortality, too [57]. Both hyperglycaemia and high glucose variability may consistently complicate the clinical course also in case of influenza A [58]. More recently, a retrospective observational study recruiting more than 7000 cases of COVID-19 from Hubei province (China) and including 952 patients with a pre-existent T2D displayed a higher mortality rate (HR 1.49), more prevalence of multiorgan damage and a greater requirement of medications (antibiotics, systemic corticosteroids, vasoactive substances, oxygen inhalation and either non-invasive or invasive mechanical ventilation) in patients with DM than in non-diabetics [59]. Interestingly, authors also found that, among T2D patients, those with better glucose control (glucose levels between 70 and $180 \mathrm{mg} / \mathrm{dl}$ ) respective to those with worse glucose control $(>180 \mathrm{mg} / \mathrm{dl})$ during hospitalization exhibited a significantly lower rate of mortality (HR $0.14 ; p<0.008$ ), and a fewer risk of progression to acute respiratory distress syndrome (HR $0.47 ; p<0.009$ ), acute kidney (HR 0.12; $p<0.046$ ) and myocardial (HR $0.24 ; p<0.01$ ) injury [59]. Similar results were found by another observation in which worse glucose control (glucose levels $>110 \mathrm{mg} / \mathrm{dl}$ ) at the admission and during hospitalization was found to be an independent risk factor for progression to critical ill or death among T2D patients with confirmed COVID-19 [60]. Therefore, hyperglycaemia represents a relevant matter in patients with COVID-19 fostering poor prognosis once the infection occurred. In addition, recent evidences suggest that SARS-CoV-2 may induce beta-cells damage thus leading to insulin secretion impairment. This phenomenon, in addition to a pre-existent hyperglycaemia and considering that systemic inflammation due to the infection exacerbates the insulin-resistance, is thought to play a significative role to further worsen glucose control and complicate the clinical course of COVID-19 [61]. In conclusion, epidemiological data suggested that DM, particularly T2D, is a frequently observed comorbidity in patients with SARS-CoV-2 infection who require hospitalization, more intensive treatment and exhibit poor prognosis or death. Poor baseline and ongoing glucose control in hospitalized patients rather than the presence of T2D per se seems to facilitate COVID-19 progression [62]. Hence, an optimal and timely blood glucose management during pandemic should be considered as an effective strategy to reduce the probability of hospitalization requirement of infected patients, and for improving the 
clinical course of those hospitalized for receiving either non-intensive or intensive care.

\section{Immune system response}

Innate and adaptive immune responses play a crucial role against viral infections [63]. Immune response against coronaviruses has been reviewed elsewhere, highlighting the role of both innate and adaptive systems to promptly contrast virus replication, facilitate virus clearance, stimulate tissue repair and develop persistent defence [64]. Immune response in COVID-19 is not still completely understood making necessary further investigation to better control the pandemic evolution [65]. However, seriously ill COVID-19 patients exhibit an exaggerate response of neutrophils and alveolar macrophages, and a relevant peripheral lymphocytes dysfunction [66], which lead to an uncontrolled viral shedding, consequent viremia and further systemic immune-mediated damage, thus triggering a harmful vicious circle [66]. Glucose levels may significantly influence immune response as observed in patients with DM. Natural killer (NK) cells activity is weakened in case of hyperglycaemia, and is inversely related with fasting plasma glucose, 2-h postprandial glycaemia and HbAlc levels [67]. Macrophage activation and phagocytosis are both decreased in patients with poor glucose control, but should be restored after an adequate optimization of metabolic control [68]. Neutrophil activation and phagocytosis are both impaired by hyperglycaemia as demonstrated in animal models and humans, thus suggesting a relevant impairment of innate immune response in patients with chronic hyperglycaemia [69]. In an animal model, obese and hyperglycaemic mice experienced higher rate of respiratory infection due to influenza and bacterial pneumonia and that was related to a lower efficient alveolar macrophage response against infections. In addition, a defective Toll-like receptor 4 signalling has been recognized in neutrophils exposed to the gram-negative lipopolysaccharide, leading to a blunted release of chemokines and cytokine, and decreased myeloperoxidase activity [69]. Moreover, T-cells function is significantly dysregulated in $\mathrm{T} 2 \mathrm{D}$ and $\mathrm{CD}^{+}$lymphocytes preferentially differentiate in $\mathrm{T}-$ helper 1 and T-helper 17 instead of T-helper 2 with a consequent imbalance between pro-inflammatory and antiinflammatory activities [70]. On the other hand, the levels of interferon gamma-which normally stimulates $\mathrm{CD}^{+}$ $\mathrm{T}$ cells maturation in sense of T-helper 1 rather than T-helper 2-were found to be lower in T2D patients sera, and can contribute in a blunted T-cell response in T2D [71]. Nevertheless, lower levels of interleukin (IL)-10 have also been described in T2D patients. Considering that IL-10 is capable to suppress the release of pro-inflammatory cytokines, lower levels of IL-10 could be related with higher IL-6-to-IFN gamma and TNF-alpha-to-IFN gamma ratios hence suggesting an enhanced activation of circulating monocytes [71]. High levels of IL-6 have been detected in diabetic patients respective to those with euglycemia, suggesting that hyperglycaemia play a crucial role in determining this immunological effect $[72,73]$. In animal models, hyperglycaemia and insulin-resistance increase the level of circulating proinflammatory cytokines and oxidative stress at baseline [74]. Since this pro-inflammatory background usually results reversible after an effective treatment of hyperglycaemia, a low dose endotoxemia consistently enhances systemic inflammation in a animal model [75]. Therefore, hyperglycaemia may predispose to an exaggerate immune response even in case of a mild-to-moderate viral load. As known, a hyperinflammatory syndrome with cytokine dysregulation has been well recognized in seriously ill patients [76], thus highlighting its crucial role in serious manifestations of COVID-19 [77]. Specific interleukins and chemokines (IL-2, IL-7, IL-6, TNF-alpha, interferon gamma induced protein 10, granulocyte-colony stimulating factor) are upregulated in patients who exhibited a worsen prognosis [78] and particularly high levels of IL-6 have been detected in case of serious pulmonary involvement or in patients requiring intensive care [79]. These findings are also more evident in elderly patients who display less vigorous immune response against viral shedding, greater susceptibility to more serious pulmonary and systemic involvement, and are finally predisposed to COVID-19 progression [80]. Both the number and function of $\mathrm{T}$ cells (both $\mathrm{CD} 4^{+}$and $\mathrm{CD} 8^{+}$) [81, 82], B cells depletion, and hypercoagulability have also been observed in seriously ill cases and the greater the magnitude of these haematological and biochemical alterations then the greater the severity of the prognosis $[83,84]$. In conclusion, diabetic patients especially elderly individuals and those with worse baseline glucose control may exhibit immune system dysregulation that predispose them to a less effective response against SARS-CoV-2 and to a dysfunctional inflammation that requires to be carefully monitored in confirmed cases of COVID-19, for preventing or avoiding a harmful progression of the disease.

\section{Pathophysiological characteristics}

Angiotensin-converting enzyme $2\left(\mathrm{ACE}_{2}\right)$ is a carboxypeptidase normally involved in the cleavage of angiotensin I and angiotensin II, and is the main receptor for SARS-CoV2 playing a determinant role in viral entry into the host, and clearly explaining both the transmissibility and severity of COVID-19 among humans [85]. $\mathrm{ACE}_{2}$ is expressed at the level of several tissues (transmembrane and soluble forms), such as lung [86], oral mucosa [87], intestine [88], brain [89], pancreatic islets [90], testis [91] and kidney [92]. 
Differentiated type 2 pneumocytes normally express $\mathrm{ACE}_{2}$, which is essential to regulate pulmonary homoeostasis and protects against pulmonary injury [93]. Indeed, low levels of $\mathrm{ACE}_{2}$ have been described in severe acute and chronic pulmonary diseases thus predisposing to poor prognosis [94]. However, $\mathrm{ACE}_{2}$ is overexpressed in chronic diseases, including T2D, and this phenomenon could be also related with chronical exposure to several medications [94, 95]. This biochemical condition is believed to facilitate the internalization of SARS-CoV-2 into pneumocytes, thus contributing to worse prognosis in COVID-19 [94, 95]. However, the role of $\mathrm{ACE}_{2}$ overexpression in worsening the prognosis is an emergent issue, and remains currently debated [96].

\section{Diabetes-related comorbidities}

Cardiovascular diseases, including coronary and cerebrovascular artery disease and heart failure, are frequently observed in T2D patients and it has been estimated that about a third of them displayed these kind of complications over time [97]. Cardiovascular system is the main extrapulmonary compartment extensively involved in COVID-19, as suggested by a frequent myocardial involvement in affected patients especially in those having hypertension, T2D and cardiovascular diseases at baseline [98]. Vascular inflammation and endothelial dysfunction [99], myocardial injury and cardiac arrhythmias are not-infrequently observed in COVID19 confirmed cases, significantly influencing the risk of poor prognosis or death in this cluster of patients [100-102].

Overweight-obesity syndrome is a multifactorial disease which significantly predispose to cardiometabolic risk, and is strictly associated with insulin-resistance, glucose metabolism impairment and T2D [103-105]. Despite obesity is usually associated with decreased risk of death in patients with severe acute respiratory distress (obesity paradox), currently available data suggest that an elevated body mass index should be considered as an independent risk factor predisposing to poor prognosis [106] and death in COVID19 [107-110]. Indeed, the prevalence rate of obesity in this cluster of patients has been reported in $42 \%$ of the cases [111] and a BMI greater than $35 \mathrm{~kg} / \mathrm{m}^{2}$ has been usually observed in patients requiring hospitalization and invasive mechanical ventilation [112] also in younger patients $(<60$ years) [113]. Pathophysiological mechanisms possibly related with poor prognosis in obese patients are not completely understood but may be attributable to a greater inflammatory background as similarly found in DM due to hyperglycaemia and insulin resistance [70]. Obesity is usually associated to other severe comorbidities with high impact on cardio-metabolic health, such as fatty liver disease, vascular inflammation, cardiovascular atherosclerotic diseases and heart failure [114] that might be related with a higher burden of lethal complications, especially in hospitalized patients with COVID-19 [115]. In addition to cardiometabolic risk factors, obese patients are more prone to have a decreased pulmonary ventilation or obstructive sleep apnoea, which predispose them to low levels of blood oxygenation at baseline and consequently to worse respiratory outcomes in case of acute infective respiratory diseases [116, 117]. Nutritional patterns usually exhibited by obese patients are frequently characterized by an elevated dietary consumption of processed food rich in saturated fat, cholesterol, sugar and a low consumption of fibres and micronutrients, such as vitamin D [118]. These dietary patterns may affect physiological microbiome composition, weaken the immune response against microbial agent and foster immune system dysfunction [115]. In addition, vitamin D deficiency/insufficiency and sedentary lifestyle, which are highly prevalent among obese patients, should be considered as predisposing factors for worse prognosis in response to acute infections, including COVID-19 [119]. Abdominal obesity usually leads to a low cardiorespiratory reserve and systemic inflammatory dysfunction which predispose to a worse prognosis in COVID-19 [120]. Conversely, regular physical exercise, which is normally lacking in an obesogenic lifestyle, is associated to higher levels of cardiorespiratory fitness, and is believed to improve the innate immune response and attenuate cytokine dysregulation often experienced by high risk patients with the so called cytokine storm [121]. Visceral obesity is also a risk factor for both the development and progression of cardiovascular diseases [114] considering that it fosters higher level of pro-thrombotic circulating factors and predisposes to thrombotic events [122]. Furthermore, visceral obesity is more prevalent in men than women and this biological phenomenon has been hypothesized to have a putative role in driven poor prognosis of COVID-19 especially in men. From this point of view, male obesity is usually associated with a functional hypogonadism and these clinical conditions are both associated with one other [123], according to a complex and multifactorial pathogenesis [124] that fosters higher baseline levels of inflammation and endothelial dysfunction [125]. Aromatase gene expression is enhanced by prostaglandin $E_{2}$, whose levels were found to be higher in visceral adipose tissue of obese men [126]. An enhanced aromatase activity at the level of adipose tissue increases local levels of estradiol that is thought to be a defensive mechanism against local inflammation and insulin resistance [127]. Whether augmented aromatase levels (and activity) at the level of adipose tissue in men may be responsible for a systemic testosterone-to-oestrogen imbalance remains questionable. However, obese men are usually affected by this biochemical condition and body mass index is inversely 
correlated to testosterone-to-oestrogen ratio [128]. A low testosterone-to-estradiol ratio contributes to increase the cardiovascular risk particularly in elderly [129] and in those with previous cardiovascular diseases [130-132]. In addition, hormonal pattern associated with visceral obesity may play a relevant role in reducing the efficacy of immune response against infectious agents, predisposing to cytokine dysregulation, endothelial dysfunction, thrombosis, finally driving patients, particularly men, to poor prognosis or death [133].

Moreover, $\mathrm{ACE}_{2}$ is also expressed on adipose cells [134] and a larger extension of adipose tissue in obese patients may significantly increase the number of available receptors for SARS-CoV-2, thus leading to a much greater viral shedding once the infection occurs [135].

In conclusion, multiple diabetes-associated chronic comorbidities, particularly obesity, have been found to worsen the prognosis in COVID-19 affected patients by acting as independent risk factors. Careful management and prompt interventions are thus required for improve clinical outcome predominantly in type 2 diabetic patients.

\section{Concomitant medications}

Pathogenetic mechanisms basically involved in SARSCoV-2 infection may be exacerbated by the use of concomitant medications for the management of T2D. Of note, an exaggerate pulmonary and systemic expression of $\mathrm{ACE}_{2}$ facilitates SARS-CoV-2 replication and may be responsible for worse clinical course and poor prognosis [94, 95]. In animal model, pioglitazone has demonstrated to increase $\mathrm{ACE}_{2}$ expression particularly at the level of hepatic and adipose tissue [136, 137]. On the other hand, the analysis of potential therapeutic targets for SARS-CoV-2 assessed by a computational model found pioglitazone to have a potential for inhibiting 3CLpro, an essential target for viral replication [138]. These findings did not provide conclusive assumption and diabetologists can safely prescribe pioglitazone taking into account general concerns including fluid retention and heart failure [139].

Gliflozins prescription is increasing over time, also considering a long-term beneficial cardiovascular and renal protection [140, 141]. Many mechanisms of cardiovascular and renal protection have been proposed, including an enhanced induction of $\mathrm{ACE}_{2}$ expression at the level of heart and kidney but it is unclear whether this effect may negatively influence clinical course in COVID-19 [142]. Moreover, despite gliflozins reduce inflammatory injury and endothelial dysfunction, none conclusive data are currently available to confirm their potential beneficial effect in diabetics with COVID-19 [143]. Concerns about gliflozins use in COVID-19 are attributable to volume contraction, renal insufficiency and increased risk of ketoacidosis that may be supposed to occur particularly in hospitalized patients, including those severely ills.

Dipeptidyl peptidase IV (DPP-IV or CD26) is a transmembrane and soluble ectopeptidase largely expressed in human tissues, including airways, lung and leucocytes [144]. Particularly, DPP-IV is specifically involved in MERS pathogenesis given that it mediate MERS-CoV-2 internalization in host cells [145]. No data actually support the role of DPP-IV in the internalization of SARS-CoV-2 and further study are needed to verify this aspect, and for demonstrating clear protective effects [146]. However, DPPIV inhibitors have shown to potentiate immune response by increasing T-cells survival, consequently enhance immune response [147], and possibly playing a relevant role in reducing the onset or progression of acute pulmonary manifestations in COVID-19 [145].

Glucagon-like peptide 1 receptor agonists (GLP-1RAs) belong to an effective class of medications approved for the treatment of T2D and for preventing diabetes-related cardiovascular and renal complications over time [148-151]. Immune response and systemic inflammation play a crucial role in SARS-CoV-2 infection, particularly in case of severe clinical course of the disease. In this clinical scenario, it is speculated that the use of GLP-1RAs could provide both a better glucose control and anti-inflammatory effects with consequent improvement of outcomes in COVID-19 affected patients [143]. In patients with pulmonary inflammation, mononuclear circulating cells express lower level of GLP-1 receptors than controls and this condition is associated with a blunted production of interferon gamma by $\mathrm{T}$ cells and NK cells. In addition, the expression of programmed death cell protein 1 , which mediates $\mathrm{T}$-cell apoptosis, is enhanced on T-cell surface and consequently the efficiency of cell-mediated immune response is weaken. Liraglutide, a once-daily administered long-acting GLP1RA, demonstrated to restore the expression of GLP-1 receptors on macrophage surface, and potentiate immunemediated response [152]. In addition, both DPP-IV pharmacological inhibition (linagliptin) and GLP-1RA (liraglutide) were found to contrast pulmonary injury, reduce platelet activation, microvascular thrombosis, and oxidative stress in mice model of endotoxemia [153]. Moreover, GLP-1RAs have been found to reduce the expression of pulmonary IL-33, thus playing an interesting role in contrasting a IL-33 mediated damage in immune-allergic diseases and viral infections [154].

Considering that pancreatic islets express $\mathrm{ACE}_{2}$, glucose impairment in COVID-19 diabetic patients could be attributable to a partial insulin deficiency [56]. However, glucose impairment could also be attributable to SARS-CoV-2 infection-induced stress or as the consequence of some medications or treatment protocols, including high-dose 
glucocorticoids, particularly used in hospitalized patients [155]. Insulin therapy is recommended in hospitalized patients [156], including those with COVID-19, and a basal-bolus respective to a sliding scale regimen should be preferred in infected patients for avoiding glycaemic excursion and greater glucose variability $[157,158]$.

Hypertension is frequently observed in T2D patients leading to a consistent increase in the risk of atherosclerotic cardiovascular and renal diseases [159]. ACE inhibitors and angiotensin receptor blockers compared to other antihypertensive medications demonstrated to be more effective to prevent or delay the onset of cardiovascular and renal complications in people with T2D, and are currently used as the first-line treatment in these patients [160, 161]. Evidence from animal models suggested that ACE inhibitors are able to increase the expression of $\mathrm{ACE}_{2}$ at the level of lung, thus leading to initial clinical concerns about the management of arterial hypertension in diabetic patients [162]. First suggestions advised to replace these medications with calciumchannel blockers in order to avoid undesirable detrimental effects of COVID-19 clinical course [95]. Nevertheless, no sufficient data supported the hypothesis that the use of renin-angiotensin system blockers may interfere with the internalization of SARS-CoV-2 in respiratory cells hence increasing its virulence [163]. In addition, ACE inhibitors and angiotensin receptor blockers protect lung, heart and kidney against inflammation, thus playing a potential beneficial role also in T2D patients with COVID-19 [164].

Statins are usually prescribed especially in T2D patients to protect against cardiovascular complications [165]. The role of statins in COVID-19 is not clearly established, however, some observation should be done. First, COVID-19 is associated with higher cardiovascular mortality specifically in patients with more risk factors, including hypertension and T2D, and statins could be useful to maintain or optimize lipid management and improve endothelial dysfunction in this clinical setting [166]. In animal models, statins inhibit the myeloid differentiation primary response 88 (MYD88) [167]. MYD88 is a protein adaptor for inflammatory signalling pathways downstream of members of Toll-like receptors and IL-1 receptor families, and plays a critical function in the activation and amplification of innate immune response [168]. The inhibition of MYD88 seems to reduce pulmonary inflammatory damage, and to improve survival in SARS$\mathrm{CoV}$ and MERS-CoV infected mice [167]. Patients with established cardiovascular disease, and those at higher risk of atherosclerotic cardiovascular disease including T2D (also in primary prevention) should be advised to maintain current statin treatment also in case of confirmed COVID-19. In patient with active COVID-19, an increased risk of muscular damage has been described and statin therapy could be interrupted for a short period of time in order to favour muscular recovery [169].

\section{Discussion and conclusions}

T2D should be considered as a risk factor for poor prognosis in COVID-19 due to several reasons, including poor baseline glucose control and high glycaemic variability, diabetes-related immune dysfunction and concurrent comorbidities, also proven to act as independent risk factors for poor prognosis in this clinical setting. Considering that respiratory system remains essentially the leading way for SARS-CoV-2 entering in host, and given that immune barriers are weaken in T2D patients, including resident pulmonary macrophages, neutrophils and $\mathrm{T}$ cells [70], diabetologists could improve clinical outcomes in COVID-19 simply by the use of such a medication with potential for positive immune-modulation and anti-inflammatory effects. Unfortunately, inconclusive deductions are currently available for considering concomitant medications favourable (as well as detrimental) factors in COVID-19 patients with T2D. Despite some putative mechanisms have been identified and some speculative hypothesis have also been formulated indicating that some anti-diabetes medications may improve clinical course in COVID-19 (pioglitazone, gliflozins, DPP-IV inhibitors, GLP-1RA), further studies are needed to clarify the issue. A timely glucose control should be obtained in diabetic patients during pandemic for the purpose to avoid potentially harmful outcomes in case of SARS-CoV-2 infection [170]. Anti-diabetic medications should be used with caution, also considering their impact on patient safety in case of complications related with COVID-19 infection (renal failure, cardio-respiratory burden, ketoacidosis, etc). Oral and non-insulin injectable medications (GLP-1RAs) should be considered to maintain or intensify household glucose control, while insulin treatment is currently known to be safer in case of hospitalized and seriously ill patients [171].

Given this consideration, in seriously ill patients, immune response should be adequately monitored in order to carefully predict or precociously diagnose a severe disease [172] and cytokines, including IL-6, may be considered as a goal for novel and more specific target therapies particularly in T2D individuals [173-175].

Beyond the risks strictly related with COVID-19 infections in diabetic patients, further concerns should be taken into account. Social distancing and lockdown have been proposed as the most effective action to prevent and reduce spread of SARS-CoV-2 infection [176]. Consequently, more time has been spent in household and access to public and private services has been consistently reduced. Thus, several barriers exist for diabetic patients to maintain an adequate fitness status and weight management as well as access to ambulatory care for obtaining adequate treatment adjustments [177]. In the last few months, home confinement led to physical inactivity and low exposure to sunlight, 
with possible detrimental effects particularly in diabetic and obese patients [119]. Physical exercise should be encouraged also at home or outdoor, even respecting social distancing rules, since it promotes weight loss, and improves cardiorespiratory fitness [121]; reduces levels of cortisol thus reinforcing immune response against infections; induces T-cell differentiation and maturation [178].

Importantly, patients should be advised about risks and supported regarding pandemic-related concerns. Particularly, they should be elucidated about general hygienic tips to protect themselves and others from SARS-CoV-2 spread; promptly recognize COVID-19 signs and symptoms; access orderly to approved testing if exposed; furthermore, it is important to avoid unnecessary routine appointment in person especially for elderly patients [179]. Closely monitoring of glucose control should be recommended at home and glucose reports should be periodically sent to the diabetologist for proper therapy adjustments [180].

The hard lesson form Lombardy disaster probably teaches to change prospective in the conception of patients care during the present and in case of further pandemic. Implementation of community-centred care system (home care and mobile clinics) may result in a prompt detection and better management of infected patients particularly for frail individuals. Moreover, it might contain an unnecessary hospital workload, letting hospital activities to focus mainly on acute cares and limiting contagion risks among inpatients and healthcare personnel. Finally, it could provide at home special cares for elderly and comorbid patients [181]. In this historical moment, the use of technologies appears certainly appropriated to better manage chronic clinical conditions, including DM [182-184]. Diabetic outpatients should be conveniently managed by means of telemedicine that includes several services such as emergency phone calls, social media messaging, teleconsulting and ambulatories should be fitted with technological tools according to patients ability, healthcare personnel characteristics and available economic resources [62].

Author contributions G.L.: project leader, manuscript writer; A.D.T.: manuscript writer; V.A.G.: manuscript reviewer; E.G.: manuscript reviewer; G.D.P.: implemented the text especially in the section dedicated to obesity; V.T.: project leader, manuscript reviewer. All authors (G.L., A.D.T., V.A.G., E.G., G.D.P and V.T.) provided literature searching, gave critical feedback and accepted the final manuscript.

\section{Compliance with ethical standards}

Conflict of interest The authors declare that they have no conflict of interest.

Publisher's note Springer Nature remains neutral with regard to jurisdictional claims in published maps and institutional affiliations.

\section{References}

1. P. Zhou, X. Lou Yang, X.G. Wang et al. A pneumonia outbreak associated with a new coronavirus of probable bat origin. Nature 579(7798), 270-273 (2020). https://doi.org/10.1038/s41586-0202012-7

2. A.E. Gorbalenya, S.C. Baker, R.S. Baric et al. The species severe acute respiratory syndrome-related coronavirus: classifying 2019-nCoV and naming it SARS-CoV-2. Nat. Microbiol. 5(4), 536-544 (2020). https://doi.org/10.1038/s41564-020-0695-z

3. P.G. Auwaerter, Coronavirus COVID-19 (SARS-CoV-2). Johns Hopkins ABX Guide (The Johns Hopkins University, 2020). https://www.hopkinsguides.com/hopkins/view/Johns_Hopkins_ ABX_Guide/540747/all/Coronavirus_COVID_19_SARS_ CoV_2_. Accessed 16 Jul 2020

4. F. Wu, S. Zhao, B. Yu et al. A new coronavirus associated with human respiratory disease in China. Nature 579(7798), 265-269 (2020). https://doi.org/10.1038/s41586-020-2008-3

5. R. Lu, X. Zhao, J. Li et al. Genomic characterisation and epidemiology of 2019 novel coronavirus: implications for virus origins and receptor binding. Lancet 395(10224), 565-574 (2020). https://doi.org/10.1016/S0140-6736(20)30251-8

6. Y.R. Guo, Q.D. Cao, Z.S. Hong et al. The origin, transmission and clinical therapies on coronavirus disease 2019 (COVID-19) outbreak-an update on the status. Mil. Med. Res. 7(1), 11 (2020). https://doi.org/10.1186/s40779-020-00240-0

7. W. Ji, W. Wang, X. Zhao, J. Zai, X. Li, Cross-species transmission of the newly identified coronavirus 2019-nCoV. J. Med. Virol. 92(4), 433-440 (2020). https://doi.org/10.1002/jmv.25682

8. Z. Liu, X. Xiao, X. Wei et al. Composition and divergence of coronavirus spike proteins and host ACE2 receptors predict potential intermediate hosts of SARS-CoV-2. J. Med. Virol. 92, 595-601 (2020). https://doi.org/10.1002/jmv.25726

9. K.G. Andersen, A. Rambaut, W.I. Lipkin et al. The proximal origin of SARS-CoV-2. Nat. Med. 26, 450-452 (2020). https:// doi.org/10.1038/s41591-020-0820-9

10. Virus origin/Reducing animal-human transmission of emerging pathogens. https://www.who.int/health-topics/coronavirus/whorecommendations-to-reduce-risk-of-transmission-of-emerging-pa thogens-from-animals-to-humans-in-live-animal-markets. Accessed 10 Apr 2020

11. W.B. Yu, G.D. Tang, L. Zhang, R.T. Corlett, Decoding the evolution and transmissions of the novel pneumonia coronavirus (SARS-CoV-2 / HCoV-19) using whole genomic data. Zool. Res. 41(3), 247-257 (2020). https://doi.org/10.24272/j.issn. 2095-8137.2020.022

12. M. Lipsitch, D.L. Swerdlow, L. Finelli, Defining the epidemiology of Covid-19 - studies needed. N. Engl. J. Med. 382(13), 1194-1196 (2020). https://doi.org/10.1056/NEJMp2002125

13. J. Sun, W.T. He, L. Wang et al. COVID-19: epidemiology, evolution, and cross-disciplinary perspectives. Trends Mol. Med. 26 (5), 483-495 (2020). https://doi.org/10.1016/j.molmed.2020.02.008

14. X. Li, J. Zai, X. Wang, Y. Li, Potential of large "first generation" human-to-human transmission of 2019-nCoV. J. Med. Virol. 92 (4), 448-454 (2020). https://doi.org/10.1002/jmv.25693

15. WHO Director-General's opening remarks at the media briefing on COVID-19-11 March 2020. https://www.who.int/dg/speeches/ detail/who-director-general-s-opening-remarks-at-the-mediabriefing-on-covid-19---11-march-2020. Accessed 10 Apr 2020

16. Y. Cao, X. Liu, L. Xiong, K. Cai, Imaging and clinical features of patients with 2019 novel coronavirus SARS-CoV-2: a systematic review and meta-analysis. J. Med. Virol. (2020). https:// doi.org/10.1002/jmv.25822

17. Z. Xu, L. Shi, Y. Wang et al. Pathological findings of COVID-19 associated with acute respiratory distress syndrome [published 
correction appears in Lancet Respir Med. 2020]. Lancet Respir. Med. 8(4), 420-422 (2020). https://doi.org/10.1016/S2213-2600 (20)30076-X

18. B. Hanley, S.B. Lucas, E. Youd et al. Autopsy in suspected COVID-19 cases. J. Clin. Pathol. 73(5), 239-242 (2020). https:// doi.org/10.1136/jclinpath-2020-206522

19. S. Tian, W. Hu, L. Niu, H. Liu, H. Xu, S.Y. Xiao, Pulmonary pathology of early-phase 2019 novel coronavirus (COVID19) pneumonia in two patients with lung cancer. J. Thorac. Oncol. 15(5), 700-704 (2020). https://doi.org/10.1016/j.jtho. 2020.02.010

20. L. Chen, M. Liu, Z. Zhang et al. Ocular manifestations of a hospitalised patient with confirmed 2019 novel coronavirus disease. Br. J. Ophthalmol. 104(6), 748-751 (2020). https://doi. org/10.1136/bjophthalmol-2020-316304

21. P. Wu, F. Duan, C. Luo et al. Characteristics of ocular findings of patients with coronavirus disease 2019 (COVID-19) in Hubei Province, China. JAMA Ophthalmol. 138(5), 575-578 (2020). https://doi.org/10.1001/jamaophthalmol.2020.1291

22. K.S. Cheung, I.F.N. Hung, P.P.Y. Chan et al. Gastrointestinal manifestations of SARS-CoV-2 infection and virus load in fecal samples From a Hong Kong Cohort: systematic review and meta-analysis. Gastroenterology $\mathbf{S 0 0 1 6 - 5 0 8 5}(20), \quad 30448-0$ (2020). https://doi.org/10.1053/j.gastro.2020.03.065

23. Y. Tian, L. Rong, W. Nian, Y. He, Review article: gastrointestinal features in COVID-19 and the possibility of faecal transmission. Aliment Pharmacol. Ther. 51(9), 843-851 (2020). https://doi.org/10.1111/apt.15731

24. F. D'Amico, D.C. Baumgart, S. Danese, L. Peyrin-Biroulet, Diarrhea during COVID-19 infection: pathogenesis, epidemiology, prevention and management. Clin. Gastroenterol. Hepatol. 18(8), 1663-1672 (2020). https://doi.org/10.1016/j. cgh.2020.04.001

25. L. Mao, H. Jin, M. Wang et al. Neurologic manifestations of hospitalized patients with coronavirus disease 2019 in Wuhan, China. JAMA Neurol. 77(6), 1-9 (2020). https://doi.org/10. 1001/jamaneurol.2020.1127

26. S. Recalcati, Cutaneous manifestations in COVID-19: a first perspective. J. Eur. Acad. Dermatol. Venereol. 34(5), e212-e213 (2020). https://doi.org/10.1111/jdv.16387

27. C. Ronco, T. Reis, Kidney involvement in COVID-19 and rationale for extracorporeal therapies. Nat. Rev. Nephrol. 16(6), 308-310 (2020). https://doi.org/10.1038/s41581-020-0284-7

28. V. Fanelli, M. Fiorentino, V. Cantaluppi et al., Acute kidney injury in SARS-CoV-2 infected patients. Crit. Care. 24(1), 155 2020). https://doi.org/10.1186/s13054-020-02872-z

29. A. Lovato, C. de Filippis, Clinical presentation of COVID-19: a systematic review focusing on upper airway symptoms. Ear Nose Throat J. (2020). https://doi.org/10.1177/0145561320920762

30. G. Tavazzi, C. Pellegrini, M. Maurelli et al. Myocardial localization of coronavirus in COVID-19 cardiogenic shock. Eur. J. Heart Fail. 22(5), 911-915 (2020). https://doi.org/10.1002/ejhf. 1828

31. Y.Y. Zheng, Y.T. Ma, J.Y. Zhang, X. Xie, COVID-19 and the cardiovascular system. Nat. Rev. Cardiol. 17(5), 259-260 (2020). https://doi.org/10.1038/s41569-020-0360-5

32. Y. Hu, H. Deng, L. Huang et al. Analysis of characteristics in death patients with COVID-19 pneumonia without underlying diseases. Acad. Radiol. 27(5), 752 (2020). https://doi.org/10. 1016/j.acra.2020.03.023

33. G. Onder, G. Rezza, S. Brusaferro, Case-fatality rate and characteristics of patients dying in relation to COVID-19 in Italy. JAMA (2020). https://doi.org/10.1001/jama.2020.4683

34. J.L. Vincent, F.S. Taccone, Understanding pathways to death in patients with COVID-19. Lancet. Respir. Med. 8(5), 430-432 (2020). https://doi.org/10.1016/S2213-2600(20)30165-X
35. Q. Ye, B. Wang, J. Mao et al. Epidemiological analysis of COVID-19 and practical experience from China. J. Med Virol. 92(7), 755-769 (2020). https://doi.org/10.1002/jmv.25813

36. Kang Y.-J. Mortality rate of infection with COVID-19 in Korea from the perspective of underlying disease. Disaster Med Public Health Prep. 1-3 (2020). https://doi.org/10.1017/dmp.2020.60

37. Z. Shahid, R. Kalayanamitra, B. McClafferty et al. COVID-19 and older adults: what we know. J. Am. Geriatr. Soc. 68(5), 926-929 (2020). https://doi.org/10.1111/jgs. 16472

38. G. Onder, G. Rezza, S. Brusaferro, Case-fatality rate and characteristics of patients dying in relation to COVID-19 in Italy. JAMA 323(18), 1775-1776 (2020). https://doi.org/10.1001/ja ma. 2020.4683

39. P. Saeedi, I. Petersohn, P. Salpea et al. Global and regional diabetes prevalence estimates for 2019 and projections for 2030 and 2045: results from the International Diabetes Federation Diabetes Atlas, 9th edition. Diabetes Res. Clin. Pract. 157, 107843 (2019). https://doi.org/10.1016/j.diabres.2019.107843

40. G.P. Fadini, M.L. Morieri, E. Longato, A. Avogaro, Prevalence and impact of diabetes among people infected with SARS-CoV2. J. Endocrinol. Investig. 43(6), 867-869 (2020). https://doi.org/ 10.1007/s40618-020-01236-2

41. J.J. Zhang, X. Dong, Y.Y. Cao et al. Clinical characteristics of 140 patients infected with SARS-CoV-2 in Wuhan, China. Allergy 75 (7), 1730-1741 (2020). https://doi.org/10.1111/all.14238

42. S.A. Meo, T. Al-Khlaiwi, A.M. Usmani et al. Biological and epidemiological trends in the prevalence and mortality due to outbreaks of novel coronavirus COVID-19. J. King Saud. Univ. Sci. 32(4), 2495-2499 (2020). https://doi.org/10.1016/j.jksus. 2020.04.004

43. N. Chow, K. Fleming-Dutra, R. Gierke et al. Preliminary estimates of the prevalence of selected underlying health conditions among patients with coronavirus disease 2019-United States, February 12-March 28, 2020. Morb. Mortal. Wkly Rep. 69(13), 382-386 (2020). https://doi.org/10.15585/mmwr.mm6913e2

44. W.J. Guan, Z.Y. Ni, Y. Hu et al. Clinical characteristics of coronavirus disease 2019 in China. N. Engl. J. Med. 382(18), 1708-1720 (2020). https://doi.org/10.1056/NEJMoa2002032

45. F. Zhou, T. Yu, R. Du et al. Articles Clinical course and risk factors for mortality of adult inpatients with COVID-19 in Wuhan, China: a retrospective cohort study. Lancet 395, 1054-1062 (2020). https://doi.org/10.1016/S0140-6736(20)30566-3

46. P.K. Bhatraju, B.J. Ghassemieh, M. Nichols et al. Covid-19 in critically ill patients in the seattle region-case series. N. Engl. J. Med. 382(21), 2012-2022 (2020). https://doi.org/10.1056/ NEJMoa2004500

47. R. Huang, L. Zhu, L. Xue et al. Clinical findings of patients with coronavirus disease 2019 in Jiangsu province, China: a retrospective, multi-center study. PLoS Negl. Trop. Dis. 14(5), e0008280 (2020). https://doi.org/10.1371/journal.pntd.0008280

48. X. Yang, Y. Yu, J. Xu et al. Clinical course and outcomes of critically ill patients with SARS-CoV-2 pneumonia in Wuhan, China: a single-centered, retrospective, observational study [published correction appears in Lancet Respir Med. 2020 Apr;8 (4):e26]. Lancet Respir. Med. 8(5), 475-481 (2020). https://doi. org/10.1016/S2213-2600(20)30079-5

49. Y. Du, L. Tu, P. Zhu et al. Clinical features of 85 fatal cases of COVID-19 from Wuhan. a retrospective observational study. Am. J. Respir. Crit. Care Med. 201(11), 1372-1379 (2020). https://doi.org/10.1164/rccm.202003-0543OC

50. W. Abu-Ashour, L.K. Twells, J.E. Valcour, J.M. Gamble, Diabetes and the occurrence of infection in primary care: a matched cohort study. BMC Infect. Dis. 18(1), 67 (2018). https://doi.org/ 10.1186/s12879-018-2975-2

51. H. Wu, E.S.H. Lau, R.C.W. Ma et al. Secular trends in all-cause and cause-specific mortality rates in people with diabetes in 
Hong Kong, 2001-2016: a retrospective cohort study. Diabetologia 63(4), 757-766 (2020). https://doi.org/10.1007/s00125019-05074-7

52. R. Allard, P. Leclerc, C. Tremblay, T.N. Tannenbaum, Diabetes and the severity of pandemic influenza A (H1N1) infection. Diabetes Care. 33(7), 1491-1493 (2010). https://doi.org/10. 2337/dc09-2215

53. R.B. Klekotka, E. Mizgała, W. Król, The etiology of lower respiratory tract infections in people with diabetes. Pneumonol. Alergol. Pol. 83(5), 401-408 (2015). https://doi.org/10.5603/ PiAP.2015.0065

54. A. Badawi, S.G. Ryoo, Prevalence of comorbidities in the Middle East respiratory syndrome coronavirus (MERS-CoV): a systematic review and meta-analysis. Int J. Infect. Dis. 49, 129-133 (2016). https://doi.org/10.1016/j.ijid.2016.06.015

55. M. Goeijenbier, T.T. van Sloten, L. Slobbe et al. Benefits of flu vaccination for persons with diabetes mellitus: a review. Vaccine 35(38), 5095-5101 (2017). https://doi.org/10.1016/j.vaccine. 2017.07.095

56. A. Hussain, B. Bhowmik, N.C. do Vale Moreira, COVID-19 and diabetes: knowledge in progress. Diabetes Res Clin. Pract. 162, 108142 (2020). https://doi.org/10.1016/j.diabres.2020.108142

57. J.A. Critchley, I.M. Carey, T. Harris et al. Glycemic control and risk of infections among people with type 1 or type 2 diabetes in a large primary care cohort study. Diabetes Care. 41(10), 2127-2135 (2018). https://doi.org/10.2337/dc18-0287

58. K.D. Hulme, L.A. Gallo, K.R. Short, Influenza virus and glycemic variability in diabetes: a killer combination? Front. Microbiol. 8, 861 (2017). https://doi.org/10.3389/fmicb.2017.00861

59. L. Zhu, Z.G. She, X. Cheng et al. Association of blood glucose control and outcomes in patients with COVID-19 and preexisting type 2 diabetes. Cell Metab. 31(6), 1068-1077 (2020). https://doi.org/10.1016/j.cmet.2020.04.021

60. J. Wu, J. Huang, G. Zhu et al. Elevation of blood glucose level predicts worse outcomes in hospitalized patients with COVID-19: a retrospective cohort study. BMJ Open Diabetes Res Care 8(1), e001476 (2020). https://doi.org/10.1136/bmjdrc-2020-001476

61. Z.H. Wu, Y. Tang, Q. Cheng, Diabetes increases the mortality of patients with COVID-19: a meta-analysis. Acta Diabetol. 1-6 (2020). https://doi.org/10.1007/s00592-020-01546-0

62. A.K. Singh, R. Gupta, A. Ghosh, A. Misra, Diabetes in COVID19: prevalence, pathophysiology, prognosis and practical considerations. Diabetes Metab. Syndr. 14(4), 303-310 (2020). https://doi.org/10.1016/j.dsx.2020.04.004

63. O. Takeuchi, S. Akira, Innate immunity to virus infection. Immunol. Rev. 227(1), 75-86 (2009). https://doi.org/10.1111/j. 1600-065X.2008.00737.X

64. G. Li, Y. Fan, Y. Lai et al. Coronavirus infections and immune responses. J. Med Virol. 92(4), 424-432 (2020). https://doi.org/ $10.1002 / \mathrm{jmv} .25685$

65. Y. Chen, L. Li, SARS-CoV-2: virus dynamics and host response. Lancet Infect. Dis. 20(5), 515-516 (2020). https://doi.org/10. 1016/S1473-3099(20)30235-8

66. H. Li, L. Liu, D. Zhang et al. SARS-CoV-2 and viral sepsis: observations and hypotheses. Lancet 395(10235), 1517-1520 (2020). https://doi.org/10.1016/S0140-6736(20)30920-X

67. J.H. Kim, K. Park, S.B. Lee et al. Relationship between natural killer cell activity and glucose control in patients with type 2 diabetes and prediabetes. J. Diabetes Investig. 10(5), 1223-1228 (2019). https://doi.org/10.1111/jdi.13002

68. A. Lecube, G. Pachón, J. Petriz et al. Phagocytic activity is impaired in type 2 diabetes mellitus and increases after metabolic improvement. G. Sesti (ed.) PLoS ONE 6(8), e23366 (2011). https://doi.org/10.1371/journal.pone.0023366

69. W.M.T. Kuwabara, C.N.F. Yokota, R. Curi, T.C. Alba-Loureiro, Obesity and type 2 diabetes mellitus induce lipopolysaccharide tolerance in rat neutrophils. Sci. Rep. 8(1), 17534 (2018). https:// doi.org/10.1038/s41598-018-35809-2

70. T. Zhou, Z. Hu, S. Yang et al. Role of adaptive and innate immunity in type 2 diabetes mellitus. J. Diabetes Res. 2018, 7457269 (2018). https://doi.org/10.1155/2018/7457269

71. R. Kartika, D. Purnamasari, S. Pradipta et al. Impact of low interferon- $\gamma$ and il-10 levels on tnf- $\alpha$ and il- 6 production by phainduced pbmcs in type 2 diabetes mellitus. J. Inflamm. Res. 13, 187-193 (2020). https://doi.org/10.2147/JIR.S245064

72. W. Guo, M. Li, Y. Dong et al. Diabetes is a risk factor for the progression and prognosis of COVID-19. Diabetes Metab. Res. Rev. (2020). https://doi.org/10.1002/dmrr.3319

73. E. Maddaloni, R. Buzzetti, Covid-19 and diabetes mellitus: unveiling the interaction of two pandemics. Diabetes Metab. Res. Rev. e33213321 (2020). https://doi.org/10.1002/dmrr.3321

74. P.R. Ling, R.J. Smith, B.R. Bistrian, Acute effects of hyperglycemia and hyperinsulinemia on hepatic oxidative stress and the systemic inflammatory response in rats. Crit. Care Med. 35(2), 555-560 (2007). https://doi.org/10.1097/01. CCM.0000253310.02180.C2

75. P.R. Ling, R.J. Smith, B.R. Bistrian, Hyperglycemia enhances the cytokine production and oxidative responses to a low but not high dose of endotoxin in rats. Crit. Care Med. 33(5), 1084-1089 (2005). https://doi.org/10.1097/01.CCM.0000163225.88827.63

76. P. Mehta, D.F. McAuley, M. Brown et al. COVID-19: consider cytokine storm syndromes and immunosuppression. Lancet 395 (10229), 1033-1034 (2020). https://doi.org/10.1016/S0140-6736 (20)30628-0

77. P. Sarzi-Puttini, V. Giorgi, S. Sirotti et al. COVID-19, cytokines and immunosuppression: what can we learn from severe acute respiratory syndrome? Clin. Exp. Rheumatol. 38(2), 337-342 (2020)

78. C. Huang, Y. Wang, X. Li et al. Clinical features of patients infected with 2019 novel coronavirus in Wuhan, China. Lancet 395(10223), 497-506 (2020). https://doi.org/10.1016/S01406736(20)30183-5

79. D. McGonagle, K. Sharif, A. O'Regan, C. Bridgewood, The role of cytokines including interleukin-6 in COVID-19 induced pneumonia and macrophage activation syndrome-like disease. Autoimmun. Rev. 19(6), 102537 (2020). https://doi.org/10.1016/ j.autrev.2020.102537

80. C. Wu, X. Chen, Y. Cai et al. Risk factors associated with acute respiratory distress syndrome and death in patients with coronavirus disease 2019 pneumonia in Wuhan, China. JAMA Intern. Med. 180(7), 1-11 (2020). https://doi.org/10.1001/jama internmed.2020.0994

81. S. Wan, Q. Yi, S. Fan et al. Characteristics of lymphocyte subsets and cytokines in peripheral blood of 123 hospitalized patients with 2019 novel coronavirus pneumonia (NCP). medRxiv (2020). https://doi.org/10.1101/2020.02.10.20021832

82. B. Diao, C. Wang, Y. Tan et al. Reduction and functional exhaustion of $\mathrm{T}$ cells in patients with coronavirus disease 2019 (COVID-19). Front. Immunol. 11, 827 (2020). https://doi.org/10. $1101 / 2020.02 .18 .20024364$

83. C.W. Tan, J.G.H. Low, W.H. Wong et al. Critically ill COVID19 infected patients exhibit increased clot waveform analysis parameters consistent with hypercoagulability. Am. J. Hematol. 95(7), E156-E158 (2020). https://doi.org/10.1002/ajh.25822

84. E. Terpos, I. Ntanasis-Stathopoulos, I. Elalamy et al. Hematological findings and complications of COVID-19. Am. J. Hematol. 95(7), 834-847 (2020). https://doi.org/10.1002/ajh.25829

85. A.C. Walls, Y.-J. Park, M.A. Tortorici, A. Wall, A.T. Mcguire, D.V. Correspondence, Structure, function, and antigenicity of the SARS-CoV-2 spike glycoprotein. Cell 181, 281-292.e6 (2020). https://doi.org/10.1016/j.cell.2020.02.058

86. I. Hamming, W. Timens, M. Bulthuis, A. Lely, G. Navis, H. van Goor, Tissue distribution of ACE2 protein, the functional 
receptor for SARS coronavirus. A first step in understanding SARS pathogenesis. J. Pathol. 203(2), 631-637 (2004). https:// doi.org/10.1002/path. 1570

87. H. Xu, L. Zhong, J. Deng et al. High expression of ACE2 receptor of 2019-nCoV on the epithelial cells of oral mucosa. Int J. Oral. Sci. 12(1), 1-5 (2020). https://doi.org/10.1038/s41368020-0074-x

88. J. Wang, S. Zhao, M. Liu et al. ACE2 expression by colonic epithelial cells is associated with viral infection, immunity and energy metabolism. medRxiv (2020). https://doi.org/10.1101/ 2020.02.05.20020545

89. N. Alenina, M. Bader, ACE2 in BRain physiology and pathophysiology: evidence from transgenic animal models. Neurochem. Res. 44(6), 1323-1329 (2019). https://doi.org/10.1007/ s11064-018-2679-4

90. D. Batlle, M.J. Soler, M. Ye, ACE2 and diabetes: ACE of ACEs? Diabetes 59(12), 2994-2996 (2010). https://doi.org/10.2337/ db10-1205

91. G.C. Douglas, M.K. O'Bryan, M.P. Hedger et al. The novel Angiotensin-Converting Enzyme (ACE) homolog, ACE2, is selectively expressed by adult leydig cells of the testis. Endocrinology 145(10), 4703-4711 (2004). https://doi.org/10.1210/ en.2004-0443

92. M.J. Soler, J. Wysocki, D. Batlle, Angiotensin-converting enzyme 2 and the kidney. Exp. Physiol. Artic. 93, 549-556 (2008). https://doi.org/10.1113/expphysiol.2007.041350

93. J. Nicholls, M. Peiris, A.C.E. Good, A.C.E. bad, do battle in lung injury, SARS. Nat. Med. 11(8), 821-822 (2005). https://doi.org/ 10.1038/nm0805-821

94. R. Pal, A.C.O.V.I.D.-19 Bhansali, Diabetes Mellitus, and ACE2: the conundrum. Diabetes Res. Clin. Pract. 162, 108132 (2020). https://doi.org/10.1016/j.diabres.2020.108132

95. L. Fang, G. Karakiulakis, M. Roth, Are patients with hypertension and diabetes mellitus at increased risk for COVID-19 infection? Lancet Respir. Med. 8(4), e21 (2020). https://doi.org/ 10.1016/s2213-2600(20)30116-8

96. A.E. Gracia-Ramos, Is the ACE2 overexpression a risk factor for COVID-19 infection? Arch. Med. Res. 51(4), 345-346 (2020). https://doi.org/10.1016/j.arcmed.2020.03.011

97. T.R. Einarson, A. Acs, C. Ludwig, U.H. Panton, Prevalence of cardiovascular disease in type 2 diabetes: a systematic literature review of scientific evidence from across the world in 20072017. Cardiovasc. Diabetol. 17(1), 83 (2018). https://doi.org/10. 1186/s12933-018-0728-6

98. M. Madjid, P. Safavi-Naeini, S.D. Solomon, O. Vardeny. Potential effects of coronaviruses on the cardiovascular system: a review. JAMA Cardiol. (2020). https://doi.org/10.1001/jamaca rdio. 2020.1286

99. C. Sardu, J. Gambardella, M.B. Morelli, X. Wang, R. Marfella, G. Santulli, Hypertension, thrombosis, kidney failure, and diabetes: is COVID-19 an endothelial disease? A comprehensive evaluation of clinical and basic evidence. J. Clin. Med. 9(5), 1417 (2020). https://doi.org/10.3390/jcm9051417

100. Z. Varga, A.J. Flammer, P. Steiger et al. Endothelial cell infection and endotheliitis in COVID-19. Lancet 395(10234), 1417-1418 (2020). https://doi.org/10.1016/S0140-6736(20)30937-5

101. R.M. Inciardi, L. Lup, G. Zaccone et al. Cardiac involvement in a patient with coronavirus disease 2019 (COVID-19). JAMA Cardiol. (2020). https://doi.org/10.1001/jamacardio.2020.1096

102. R.O. Bonow, G.C. Fonarow, P.T. O'Gara, C.W. Yancy, Association of coronavirus disease 2019 (COVID-19) with myocardial injury and mortality. JAMA Cardiol. (2020). https://doi. org/10.1001/jamacardio.2020.1105

103. S.E. Kahn, R.L. Hull, K.M. Utzschneider, Mechanisms linking obesity to insulin resistance and type 2 diabetes. Nature $\mathbf{4 4 4}$ (7121), 840-846 (2006). https://doi.org/10.1038/nature05482
104. N. Napoli, P. Pozzilli, Obesity and glucose metabolism. Multidisciplinary Approach to Obesity: Assessment to Treatment. (Springer International Publishing, 2015), pp. 107-119. https:// doi.org/10.1007/978-3-319-09045-0_11

105. P. González-Muniesa, M.-A. Mártinez-González, F.B. Hu et al. Obesity. Nat. Rev. Dis Prim. 3(1), 17034 (2017). https://doi.org/ 10.1038/nrdp.2017.34

106. J. Yang, J. Hu, C. Zhu, Obesity aggravates COVID-19: a systematic review and meta-analysis [published online ahead of print]. J. Med. Virol. (2020). https://doi.org/10.1002/jmv.26237.

107. W. Dietz, C. Santos-Burgoa, Obesity and its implications for COVID-19 mortality. Obesity 28(6), 1005 (2020). https://doi. org/10.1002/oby.22818

108. D.H. Ryan, E. Ravussin, S. Heymsfield, COVID 19 and the patient with obesity-the editors speak out. Obesity 28(5), 847 (2020). https://doi.org/10.1002/oby.22808

109. R.J. Jose, A. Manuel, Does coronavirus disease 2019 disprove the obesity paradox in acute respiratory distress syndrome? Obesity 28(6), 1007 (2020). https://doi.org/10.1002/oby.22835

110. C.M. Petrilli, S.A. Jones, J. Yang et al. Factors associated with hospitalization and critical illness among 4,103 patients with COVID-19 disease in New York City. MedRxiv (2020). https:// doi.org/10.1101/2020.04.08.20057794

111. S. Richardson, J.S. Hirsch, M. Narasimhan et al. Presenting characteristics, comorbidities, and outcomes among 5700 patients hospitalized with COVID-19 in the New York City area. JAMA 323(20), 2052-2059 (2020). https://doi.org/10.1001/ja ma. 2020.6775

112. A. Simonnet, M. Chetboun, J. Poissy et al. High prevalence of obesity in severe acute respiratory syndrome coronavirus-2 (SARS-CoV-2) requiring invasive mechanical ventilation. Obesity 28(7), 1195-1199 (2020). https://doi.org/10.1002/oby.22831

113. J. Lighter, M. Phillips, S. Hochman et al. Obesity in patients younger than 60 years is a risk factor for Covid-19 hospital admission. Clin. Infect. Dis. (2020), https://doi.org/10.1093/cid/ ciaa415

114. G. De Pergola, A. Nardecchia, V.A. Giagulli et al. Obesity and heart failure. Endocr. Metab. Immune Disord. Drug Targets 13(1), 51-57 (2013). https://doi.org/10.2174/1871530311313010007

115. D. Petrakis, D. Margină, K. Tsarouhas et al. Obesity-a risk factor for increased COVID-19 prevalence, severity and lethality (Review). Mol. Med. Rep. 22(1), 9-19 (2020). https://doi.org/10. 3892/mmr.2020.11127

116. N. Stefan, A.L. Birkenfeld, M.B. Schulze, D.S. Ludwig, Obesity and impaired metabolic health in patients with COVID-19. Nat. Rev. Endocrinol. 16(7), 341-342 (2020). https://doi.org/10.1038/ s41574-020-0364-6

117. A.E. Dixon, U. Peters, The effect of obesity on lung function. Expert Rev Respir. Med. 12(9), 755-767 (2018). https://doi.org/ 10.1080/17476348.2018.1506331

118. M.J. Butler, R.M. Barrientos, The impact of nutrition on COVID-19 susceptibility and long-term consequences. Brain Behav. Immun. 87, 53-54 (2020). https://doi.org/10.1016/j.bbi. 2020.04.040

119. S.J. Carter, M.N. Baranauskas, A.D. Fly, Considerations for obesity, vitamin $\mathrm{D}$, and physical activity amid the COVID-19 pandemic. Obesity 28(7), 1176-1177 (2020). https://doi.org/10. 1002/oby. 22838

120. N. Sattar, I.B. McInnes, J.J.V. McMurray, Obesity is a risk factor for severe COVID-19 infection: multiple potential mechanisms. Circulation 142(1), 4-6 (2020). https://doi.org/10.1161/ CIRCULATIONAHA.120.047659

121. H. Zbinden-Foncea, M. Francaux, L. Deldicque, J.A. Hawley, Does high cardiorespiratory fitness confer some protection against pro-inflammatory responses after infection by SARSCoV-2? Obesity (2020). https://doi.org/10.1002/oby.22849 
122. G. De Pergola, N. Pannacciulli, Coagulation and fibrinolysis abnormalities in obesity. J. Endocrinol. Investig. 25(10), 899-904 (2002). https://doi.org/10.1007/BF03344054

123. O. Seyam, J. Gandhi, G. Joshi et al. Obesity's role in secondary male hypogonadism: a review of pathophysiology and management issues. SN Compr. Clin. Med. 1(6), 408-418 (2019). https://doi.org/10.1007/s42399-019-00056-7

124. V.A. Giagulli, J.M. Kaufman, A. Vermeulen, Pathogenesis of the decreased androgen levels in obese men. J. Clin. Endocrinol. Metab. 79(4), 997-1000 (1994). https://doi.org/10.1210/jcem.79. 4.7962311

125. G. Corona, S. Bianchini, A. Sforza et al. Hypogonadism as a possible link between metabolic diseases and erectile dysfunction in aging men. Hormones 14(4), 569-578 (2015). https://doi. org/10.14310/horm.2002.1635

126. E.R. Simpson, S.R. Davis, Minireview: aromatase and the regulation of estrogen biosynthesis-some new perspectives. Endocrinology 142(11), 4589-4594 (2001). https://doi.org/10. 1210/endo.142.11.8547

127. C. Ohlsson, A. Hammarstedt, L. Vandenput et al. Increased adipose tissue aromatase activity improves insulin sensitivity and reduces adipose tissue inflammation in male mice. Am. J. Physiol. Metab. 313(4), E450-E462 (2017). https://doi.org/10. 1152/ajpendo.00093.2017

128. H.K. Lee, J.K. Lee, B. Cho, The role of androgen in the adipose tissue of males. World J. Mens. Health 31(2), 136-140 (2013). https://doi.org/10.5534/wjmh.2013.31.2.136

129. V.A. Giagulli, M. Castellana, G. Lisco, V. Triggiani, Critical evaluation of different available guidelines for late-onset hypogonadism. Andrology (2020). https://doi.org/10.1111/andr.12850

130. Y. Gong, H. Xiao, C. Li et al. Elevated T/E2 ratio is associated with an increased risk of cerebrovascular disease in elderly men. PLoS ONE 8(4), e61598 (2013). https://doi.org/10.1371/journal. pone.0061598

131. I.D. van Koeverden, M. de Bakker, S. Haitjema et al. Testosterone to oestradiol ratio reflects systemic and plaque inflammation and predicts future cardiovascular events in men with severe atherosclerosis. 115(2), 453-462 (2019). https://doi.org/ $10.1093 /$ cvr/cvy 188

132. V.A. Giagulli, E. Guastamacchia, G. De Pergola et al. Testosterone deficiency in male: a risk factor for heart failure. Endocr. Metab. Immune Disord. Targets 13(1), 92-99 (2013). https://doi. org/10.2174/1871530311313010011

133. V.A. Giagulli, E. Guastamacchia, T. Magrone et al. Worse progression of COVID-19 in men: is testosterone a key factor? Andrology (2020). https://doi.org/10.1111/andr.12836

134. R. Kassir, Risk of COVID-19 for patients with obesity. Obes. Rev. 21(6), e13034 (2020). https://doi.org/10.1111/obr.13034

135. P.M. Ryan, N.M. Caplice, Is adipose tissue a reservoir for viral spread, immune activation, and cytokine amplification in coronavirus disease 2019? Obesity 28(7), 1191-1194 (2020). https://doi.org/10.1002/oby.22843

136. W. Zhang, C. Li, B. Liu et al. Pioglitazone upregulates hepatic angiotensin converting enzyme 2 expression in rats with steatohepatitis. Ann. Hepatol. 12(6), 892-900 (2013)

137. W. Zhang, Y.Z. Xu, B. Liu et al. Pioglitazone upregulates angiotensin converting enzyme 2 expression in insulin-sensitive tissues in rats with high-fat diet-induced nonalcoholic steatohepatitis. ScientificWorldJournal 2014, 603409 (2014). https://doi. org/10.1155/2014/603409

138. C. Wu, Y. Liu, Y. Yang et al. Analysis of therapeutic targets for SARS-CoV-2 and discovery of potential drugs by computational methods [published online ahead of print]. Acta Pharm. Sin. B. 10 (5), 766-788 (2020). https://doi.org/10.1016/j.apsb.2020.02.008

139. R.W. Nesto, D. Bell, R.O. Bonow et al. Thiazolidinedione use, fluid retention, and congestive heart failure: a consensus statement from the American Heart Association and American Diabetes Association. Diabetes Care 27(1), 256-263 (2004). https://doi.org/10.2337/diacare.27.1.256

140. A.D. Association, 9. Pharmacologic approaches to glycemic treatment: standards of medical care in diabetes-2020. Diabetes Care 43, S98-S110 (2020). https://doi.org/10.2337/dc20-S009

141. A.J. Garber, Y. Handelsman, G. Grunberger et al. Consensus statement by the american association of clinical endocrinologists and american college of endocrinology on the comprehensive type 2 diabetes management algorithm-2020 executive summary. Endocr. Pract. 26(1), 107 (2020). https://doi.org/10. 4158/CS-2019-0472

142. R. Pal, S.K. Bhadada, Should anti-diabetic medications be reconsidered amid COVID-19 pandemic? Diabetes Res. Clin. Pract. 163, 108146 (2020). https://doi.org/10.1016/j.diabres.2020.108146

143. A. Ceriello, A.P. Stoian, M. Rizzo, COVID-19 and diabetes management: What should be considered? Diabetes Res. Clin. Pract. 163, 108151 (2020). https://doi.org/10.1016/j.diabres. 2020.108151

144. D.K. Meyerholz, A.M. Lambertz, P.B. McCray, Dipeptidyl peptidase 4 distribution in the human respiratory tract implications for the middle east respiratory syndrome. Am. J. Pathol. 186(1), 78-86 (2016). https://doi.org/10.1016/j.ajpath.2015.09.014

145. G. Iacobellis. COVID-19 and diabetes: can DPP4 inhibition play a role? Diabetes Res. Clin. Pract. 162(2020). https://doi.org/10. 1016/j.diabres.2020.108125

146. M. Letko, A. Marzi, V. Munster, Functional assessment of cell entry and receptor usage for SARS-CoV-2 and other lineage B betacoronaviruses. Nat. Microbiol. 5(4), 562-569 (2020). https:// doi.org/10.1038/s41564-020-0688-y

147. M.F. Bassendine, S.H. Bridge, G.W. McCaughan, M.D. Gorrell. COVID-19 and comorbidities: a role for dipeptidyl peptidase 4 (DPP4) in disease severity? J. Diabetes (2020). https://doi.org/ 10.1111/1753-0407.13052

148. E. Standl, O. Schnell, Treatment paradigm shifting implications of recent cardiovascular outcome trials: Core insights on the brink of the 2020ies. Diabetes Res. Clin. Pract. 161(2020). https://doi.org/10.1016/j.diabres.2020.108054

149. K.H. Sheahan, E.A. Wahlberg, M.P. Gilbert, An overview of GLP-1 agonists and recent cardiovascular outcomes trials. Postgrad. Med J. 96(1133), 156-161 (2020). https://doi.org/10. 1136/postgradmedj-2019-137186

150. S. Lim, T.J. Oh, J. Dawson, N. Sattar, Diabetes drugs and stroke risk: Intensive versus conventional glucose-lowering strategies, and implications of recent cardiovascular outcome trials. Diabetes Obes. Metab. 22(1), 6-15 (2020). https://doi.org/10.1111/dom.13850

151. E.M. Varin, B.A. McLean, J.A. Lovshin, Glucagon-like peptide1 receptor agonists in adult patients with type 2 diabetes: review of cardiovascular outcome trials. Can. J. Diabetes 44(1), 68-77 (2020). https://doi.org/10.1016/j.jcjd.2019.08.011

152. J. Huang, H. Yi, C. Zhao et al. Glucagon-like peptide-1 receptor (GLP-1R) signaling ameliorates dysfunctional immunity in COPD patients. Int. J. Copd. 13, 3191-3202 (2018). https://doi. org/10.2147/COPD.S175145

153. S. Steven, K. Jurk, M. Kopp et al. Glucagon-like peptide-1 receptor signalling reduces microvascular thrombosis, nitrooxidative stress and platelet activation in endotoxaemic mice. $\mathrm{Br}$. J. Pharmacol. 174(12), 1620-1632 (2017). https://doi.org/10. 1111/bph.13549

154. M.H. Bloodworth, M. Rusznak, C.C. Pfister et al. Glucagon-like peptide 1 receptor signaling attenuates respiratory syncytial virus-induced type 2 responses and immunopathology. J. Allergy Clin. Immunol. 142(2), 683-687 (2018). https://doi.org/ 10.1016/j.jaci.2018.01.053

155. S. Gentile, F. Strollo, A. Ceriello, COVID-19 infection in Italian people with diabetes: lessons learned for our future (an 
experience to be used). Diabetes Res Clin. Pract. 162, 108137 (2020). https://doi.org/10.1016/j.diabres.2020.108137

156. S.O. Butler, I.F. Btaiche, C. Alaniz, Relationship between hyperglycemia and infection in critically ill patients. Pharmacotherapy $\mathbf{2 5}$ (7), 963-976 (2005). https://doi.org/10.1592/phco.2005.25.7.963

157. G.E. Umpierrez, A. Palacio, D. Smiley, Sliding Scale Insulin Use: Myth or Insanity? Am. J. Med. 120(7), 563-567 (2007). https://doi.org/10.1016/j.amjmed.2006.05.070

158. G.E. Umpierrez, D. Smiley, A. Zisman et al. Randomized study of basal-bolus insulin therapy in the inpatient management of patients with type 2 diabetes (RABBIT 2 Trial). Diabetes Care 30(9), 2181-2186 (2007). https://doi.org/10.2337/dc07-0295

159. J.R. Petrie, T.J. Guzik, R.M. Touyz, Diabetes, Hypertension, and cardiovascular disease: clinical insights and vascular mechanisms. Can. J. Cardiol. 34(5), 575-584 (2018). https://doi.org/10. 1016/j.cjca.2017.12.005

160. I.H. De Boer, S. Bangalore, A. Benetos et al. Diabetes and hypertension: a position statement by the American diabetes association. Diabetes Care 40(9), 1273-1284 (2017). https://doi. org/10.2337/dci17-0026

161. G. Wang, Y. Chen, L. Li et al. First-line renin-angiotensin system inhibitors vs. other first-line antihypertensive drug classes in hypertensive patients with type 2 diabetes mellitus. J. Hum. Hypertens. 32(7), 494-506 (2018). https://doi.org/10.1038/ s41371-018-0066-x

162. R. Sommerstein, M.M. Kochen, F.H. Messerli, C. Gräni, Coronavirus disease 2019 (COVID-19): do angiotensin-converting enzyme inhibitors/angiotensin receptor blockers have a biphasic effect? J. Am. Heart Assoc. 9(7), e016509 (2020). https://doi.org/ 10.1161/JAHA.120.016509

163. A.H.J. Danser, M. Epstein, D. Batlle, Renin-angiotensin system blockers and the COVID-19 pandemic: at present there is no evidence to abandon renin-angiotensin system blockers. Hypertension 75(6), 1382-1385 (2020). https://doi.org/10.1161/ HYPERTENSIONAHA.120.15082

164. E.L. Schiffrin, J.M. Flack, S. Ito, P. Muntner, R.C. Webb, Hypertension and COVID-19. Am. J. Hypertens. 33(5), 373-374 (2020). https://doi.org/10.1093/ajh/hpaa057

165. M. Bengaluru Jayanna, J.G. Robinson, The extent to which statins have improved cardiovascular outcomes: Lessons from randomized trials and observational studies of "real world" practice in people with diabetes. Diabetes Obes. Metab. 21(S1), 17-27 (2019). https://doi.org/10.1111/dom.13701

166. I. Altun, F. Oz, S.C. Arkaya et al. Effect of statins on endothelial function in patients with acute coronary syndrome: a prospective study using adhesion molecules and flow-mediated dilatation. J. Clin. Med. Res. 6(5), 354-361 (2014). https://doi.org/10.14740/ jocmr1863w

167. S. Yuan, Statins may decrease the fatality rate of middle east respiratory syndrome infection. mBio 6(4), e01120 (2015). https://doi.org/10.1128/mBio.01120-15

168. J. Deguine, G.M. Barton, MyD88: A central player in innate immune signaling. F1000Prime Rep. 6, 97 (2014). https://doi. org/10.12703/P6-97

169. Is there a role for statin therapy in acute viral infections? American College of Cardiology. https://www.acc.org/latest-in-cardiology/a rticles/2020/03/18/15/09/is-there-a-role-for-statin-therapy-in-a cute-viral-infections-covid-19. Accessed 22 Apr 2020.

170. A. Wang, W. Zhao, Z. Xu, J. Gu, Timely blood glucose management for the outbreak of 2019 novel coronavirus disease
(COVID-19) is urgently needed. Diabetes Res. Clin. Pract. 162, 108118 (2020). https://doi.org/10.1016/j.diabres.2020.108118

171. S.R. Bornstein, F. Rubino, K. Khunti et al. Practical recommendations for the management of diabetes in patients with COVID-19. Lancet Diabetes Endocrinol. 8(6), 546-550 (2020). https://doi.org/10.1016/S2213-8587(20)30152-2

172. B.M. Henry, M.H.S. de Oliveira, S. Benoit et al. Hematologic, biochemical and immune biomarker abnormalities associated with severe illness and mortality in coronavirus disease 2019 (COVID-19): a meta-analysis. Clin. Chem. Lab Med. 58(7), 1021-1028 (2020). https://doi.org/10.1515/cclm-2020-0369

173. B. Russell, C. Moss, G. George et al. Associations between immune-suppressive and stimulating drugs and novel COVID-19a systematic review of current evidence. Ecancermedicalscience 14, 1022 (2020). https://doi.org/10.3332/ecancer.2020.1022

174. L. Lin, L. Lu, W. Cao, T. Li, Hypothesis for potential pathogenesis of SARS-CoV-2 infection-a review of immune changes in patients with viral pneumonia. Emerg. Microbes Infect. 9(1), 727-732 (2020). https://doi.org/10.1080/22221751.2020.1746199

175. B. Liu, M. Li, Z. Zhou et al. Can we use interleukin-6 (IL-6) blockade for coronavirus disease 2019 (COVID-19)-induced cytokine release syndrome (CRS)? J. Autoimmun. 111, 102452 (2020). https://doi.org/10.1016/j.jaut.2020.102452

176. R.M. Anderson, H. Heesterbeek, D. Klinkenberg, T.D. Hollingsworth, How will country-based mitigation measures influence the course of the COVID-19 epidemic? Lancet 395(10228), 931-934 (2020). https://doi.org/10.1016/S0140-6736(20)30567-5

177. D.C. Klonoff, G.E. Umpierrez, Letter to the Editor: COVID-19 in patients with diabetes: risk factors that increase morbidity. Metabolism 108, 154224 (2020). https://doi.org/10.1016/j.meta bol.2020.154224

178. Exercise, immunity and the COVID-19 pandemic. https://www. acsm.org/blog-detail/acsm-blog/2020/03/30/exercise-immunitycovid-19-pandemic. Accessed 21 Apr 2020.

179. M. Puig-Domingo, M. Marazuela, A. Giustina, COVID-19 and endocrine diseases. A statement from the European Society of Endocrinology. Endocrine 68(1), 2-5 (2020). https://doi.org/10. 1007/s12020-020-02294-5

180. AACE Position Statement: Coronavirus (COVID-19) and People with Diabetes. (American Association of Clinical Endocrinologists, 2020). https://www.aace.com/recent-news-and-updates/aa ce-position-statement-coronavirus-covid-19-and-people-dia betes-updated. Accessed 21 Apr 2020

181. M. Nacoti, A. Ciocca, A. Giupponi et al. At the epicenter of the Covid-19 pandemic and humanitarian crises in Italy: changing perspectives on preparation and mitigation. NEJM Catalyst innovations in care delivery (2020). https://doi.org/10.1056/ CAT.20.0080

182. H.R. Murphy, Managing diabetes in pregnancy before, during, and after COVID-19. Diabetes Technol. Ther. 22(6), 454-461 (2020). https://doi.org/10.1089/dia.2020.0223

183. R.M. Anjana, R. Pradeepa, M. Deepa et al. Acceptability and utilization of newer technologies and effects on glycemic control in type 2 diabetes: lessons learnt from lockdown. Diabetes Technol Ther. (2020). https://doi.org/10.1089/dia.2020.0240

184. H. McGloin, D. O’Connell, M. Glacken et al. Patient empowerment using electronic telemonitoring with telephone support in the transition to insulin therapy in adults with type 2 diabetes: observational, pre-post, mixed methods study. J. Med. Internet Res. 22(5), e16161 (2020). https://doi.org/10.2196/16161 